\title{
The Ecological Footprint Depth: preliminary consideration for national accounting
}

\author{
V. Niccolucci, S. Bastianoni \& E. Tiezzi \\ Department of Chemistry, Ecodynamics Group, University of Siena, Italy
}

\begin{abstract}
Natural capital is becoming a limiting factor to human well-being and definitively to sustainability: ecological overshoot, an ineludible reality, is one of the most important evidence of it. Maintaining (and investing in) capital natural is essential to secure living condition on this planet. For this reason the differentiation between the use of natural capital flows and the depletion of natural capital stock is becoming matter of particular interest in sustainability theory. In our previous work (How deep is the footprint? A 3D representation 2009) we proposed a variant to the traditional Ecological Footprint framework, to capture for these two opposite concepts. In particularly a 3D-EF model was presented and a new dimension called Ecological Footprint Depth of simply Depth was introduced.

The aim of this paper is to propose an adaptation of the model for the national level. A theoretical explanation on how to distinguish the two components is also offered. Two nations, Italy and the USA, were considered as reference for this study.
\end{abstract}

Keywords: Ecological Footprint, flow, footprint depth, footprint size, stock, sustainability.

\section{Introduction}

Wackernagel and Rees [2] and Rees [3] introduced the Ecological Footprint (hereafter EF) as an indicator able to account for both direct and indirect land requirement needed to produce a good or to sustain population consumption. Its unit is expressed in terms of global hectare (gha) [4]. One global hectare is not just a physical hectare but a normalized hectare with world average productivity [5]. 
In this sense EF is a space-based indicator where the dimension of the foot (or its size) is directly related to the human pressure. The higher the footprint value the higher the appropriation of natural resources and ecological services.

This model is based upon the assumption that resources are provided indefinitely [2]. On the contrary resource consumption is constrained by the Earth limits. As the space available on the Earth is finite, the resources annually available are finite too.

The latest data produced by Global Footprint Network [6-8] referred that Earth is actually operating in a state of overshoot, or, in other words more resources than available are consumed. This situation is permitted if at least one of the following conditions is possible [4]:

i) the importation of biologically productive space from other region (when possible);

ii) the overuse of domestic and/or global resources.

As Earth is considered a thermodynamically closed system, it is not able to exchange matter with other planets. This automatically means that human population is actually operating an overconsumption of resources by depleting the stocks. But, while flows can be consumed totally because they are annually regenerate, stocks should be held constant over time [9] in order to guarantee the flow regeneration.

The new 3D EF vision was introduced by Niccolucci et al. [1] to appraise the flow/stock distinction. In this model two parameters, and not just one, were considered relevant:

i) the footprint size $\left(\mathrm{EF}_{\text {size }}\right)$ or the spatial component deals with the flow or the so called income of the natural capital;

ii) the footprint depth $\left(\mathrm{EF}_{\mathrm{depth}}\right)$ or the temporal component deals with the depletion of the natural capital stocks.

The components have different units: the former is a traditional footprint so it is measured in global hectares (gha) and plotted in the (x,y) plane. The latter accounts for the number of years that would theoretically be necessary to regenerate the natural capital used in one year. It is plotted in the $\mathrm{z}$ axis and represents the height of a hypothetical cylinder.

The model was preliminarily presented for Earth. But more insight on sustainability issue can be extract when the model is applied at the national level.

The aim of this paper is to propose an adaptation of the model presented to a national level and discuss on its merits and limitations. A case study was also included to support our consideration.

\section{Methods}

From a thermodynamic and ecosystemic point of view, a nation can be considered as open system able to exchange both material and energy with its surrounding environment. This exchange is essential to guarantee its survival in the long period. In the Footprint method this aspect can be appraised by 
monitoring the total lands need to satisfy the consumption, both real (i.e., locally available) and ghost (i.e., wherever located in the world).

The model early proposed was calibrated for the Earth, so it needs to be adapted in order to include new variables able to take into account for national swap.

So it was assumed the total EF as disaggregated in two components on the basis of the origin: local $\left(\mathrm{EF}_{\mathrm{loc}}\right)$ or global $\left(\mathrm{EF}_{\mathrm{glob}}\right)$, that is imported from outside.

$$
\mathrm{EF}_{\text {tot }}=\mathrm{EF}_{\text {loc }}+\mathrm{EF}_{\text {glob }}
$$

Yet each component can be divided into two further components on the basis of the kind of resources consumed (if flow or stock). The EF local term can be written as:

where:

$$
\mathrm{EF}_{\mathrm{loc}}=\mathrm{ULB}+\mathrm{ULS}
$$

ULB: is the Use (partial or total) of Local Biocapacity;

ULS: is the Use of Local Stocks;

Similarly, for the global term:

where:

$$
\mathrm{EF}_{\text {glob }}=\mathrm{UIB}+\mathrm{UIS}
$$

UIB: is the Use of Imported Biocapacity

UIS: is the Use of Imported Stocks.

Then, the total Ecological Footprint can be seen as the sum of four terms:

$$
\mathrm{EF}_{\text {tot }}=(\mathrm{ULB}+\mathrm{ULS})+(\mathrm{UIB}+\mathrm{UIS})
$$

The evaluation of each of the four components was possible by analyzing the template of the respective country, elaborated by Global Footprint Network within the National Footprint and Biocapacity Account program. In this case, the licensed version 2005 Edition rev. 2 was used. In this document, a detailed inventory of production, import, export, stock exchange and consumption movement for each input and land category was provided. This allows us to elaborate our model.

Starting from this consideration it is then possible to differentiate and evaluate the Footprint size component from the Footprint Depth.

The Footprint size or spatial term is given by the sum of both local and imported biocapacity (see eqn (5)), and plotted in the $(x, y)$ plane.

$$
\mathrm{EF}_{\text {size }}=\mathrm{ULB}+\mathrm{UIB}
$$

According to the definition proposed by Niccolucci et al. [1], the Footprint depth is given by one plus the contribution of the local and global deficit with respect to their biocapacity, as reported below:

$$
\mathrm{EF}_{\text {depth }}=1+\frac{\mathrm{ED}_{\text {loc }}}{\mathrm{BC}_{\text {loc }}}+\frac{\mathrm{ED}_{\text {glob }}}{\mathrm{BC}_{\text {glob }}}
$$


where the term 1 represents the so called natural depth, or the depth annually regenerated by the biosphere.

This component is plotted in the $z$ axes.

Naturally the relationship, reported in equation 7, should always be respected, because the traditional footprint and the 3D-EF method must produce the same value.

$$
\mathrm{EF}_{\text {tot }}=\mathrm{EF}_{\text {size }} * \mathrm{EF}_{\text {depth }}
$$

\section{Results and discussion}

From classic EF approach some interesting information can be tracked about the environmental sustainability of the two nations analyzed.

USA reported an EF value (9.7 gha per person) more than double with respect to Italy (4.0 gha per person) [6]. Those values are over than world average value (2.2 gha per person) [6] and they are quite typical for industrialized country.

USA benefited of a Biocapacity (4.7 gha per person) four times as large as Italy $\left(\mathrm{BC}_{\text {Italy }}=1.1 \mathrm{gha} /\right.$ person $)$ [6] especially due to lower population density $\left(\right.$ density $_{\text {Italy }}=194$ people $\mathrm{km}^{-2}$ and density ${ }_{\mathrm{USA}}=31$ people $\mathrm{km}^{-2}$ ).

When the ecological budget is evaluated, both nations were found in a state of ecological deficit (ED). USA shows an almost double ED with respect to Italy. Energy land is the main stressed land category for both nations.

The time series of the EF and BC parameters were also qualitatively observed since 1961 to 2003. Data was shown in Figure 1.

The trend observed is for both unambiguous: the gap between $\mathrm{EF}$ and $\mathrm{BC}$ is constantly increasing without flexions. The difference between the two trends is just on the position of the cross line point. While for USA the gap started around the 1970s, Italy operates in a state of overshoot before 1960. The first important indication is that both Italian and American population annually consumed more resources than available in 2003 .

The slope reveals the entity of the resource request (EF) with respect to local availability (BC). Also in this case the two countries report different behavior.

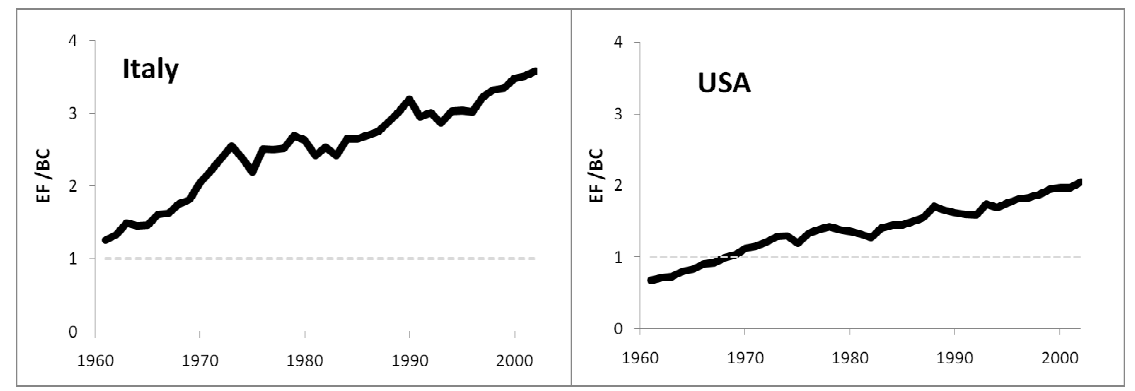

Figure 1: Time series of Ecological Footprint (dark line) and Biocapacity (dotted line) of Italy (left) and the United State of America (right). Sources: Global Footprint Network, 2005. 
USA reported a lower slope mainly due to the fact that USA enjoys a greater (at least twice) $\mathrm{BC}$ with respect to Italy.

By the application of the method proposed a more exhaustive picture on the state of sustainability of the two countries can be drawn. In this paper, for simplicity and clarity, all considerations are referred to one single year (i.e. 2003) but the same argumentation can be repeated for the entire period considered.

The total EF was then disaggregated in four components to establish both the provenience (if global or local) and the kind (if flow or stock) of the resources and ecological services really consumed by the population.

As reported in Figure 2, the two profiles are quite different.

According to the provenience, Italy takes the half of the total resources and ecosystems services consumed from local areas (ULB + ULS) and the other half from external areas everywhere located (UIB + UIS). USA used much more local resources and ecosystem services (85\%) than Italy (50\%), while just the $15 \%$ derived from outside.

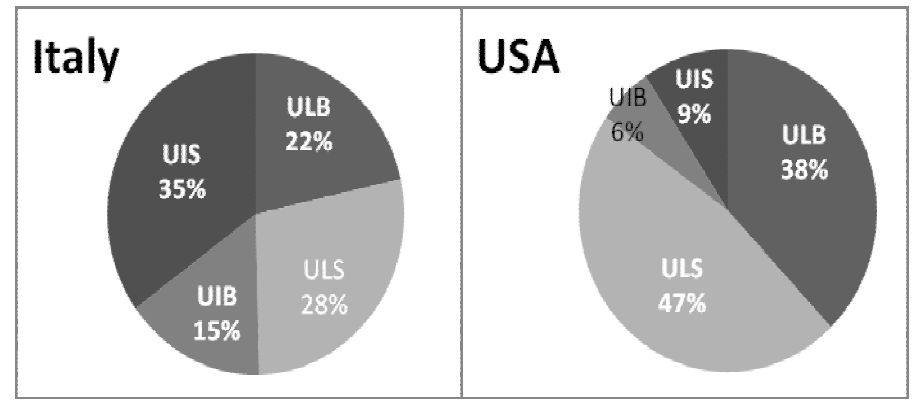

Figure 2: $\quad$ EF disaggregation based on the origin (local or global) and on the kind (flow or stock) of the resources and ecosystem services.

From this perspective, the survival of Italian population is guaranteed by a huge quantity of ghost lands, and then resources, imported from outside, while USA strategy was to live essentially on self-forces.

A country with high values of the global component of total EF can be considered to be brittle system with low resilience and a high dependence from other countries to which it transfer a part of its unsustainability.

With regard to the flow-stock distinction, results (see again Figure 2) revealed that Italy is more based on stock depletion (63\%) than flow consumption $(37 \%)$. In addition it has been estimated that the stocks derive mainly from external sources $(35 \%)$ while the residual $28 \%$ have a local provenience. On the contrary, the flows used have a local nature for $22 \%$.

Also population consumption of USA is based on stock depletion (56\%), but with lower percentage with respect to Italy. Most of the stocks have local origin (47\%). Also flows used derive from local sources (44\%). 
All these considerations can be condensate inside the two indices calculated, $\mathrm{EF}_{\text {space }}$ and $\mathrm{EF}_{\text {depth }}$, whose values are reported in Table 1.

Although the USA reported a total footprint more than double with respect to Italy, a preliminary analysis of both $\mathrm{EF}_{\text {size }}$ and $\mathrm{EF}_{\text {depth }}$ could induce to consider the USA "more virtuous". This is linked to two main aspects of USA consumption patterns:

i) it is mostly based on the use of flows (i.e. resources and ecological services that are annually regenerated) as confirmed by the high value of $\mathrm{EF}_{\text {size }}$;

ii) it is less stock dependent than Italy as determined by the respective $\mathrm{EF}_{\text {depth }}$ values.

However, these considerations are not totally exhaustive. In fact the (un)sustainability is an extensive problem, hence the contribution of the number of inhabitants and their total consumption must be taken into account.

Table 1: $\quad$ The main Footprint parameters for Italy and the USA.

\begin{tabular}{c|ccc|cc}
\hline & $\begin{array}{c}\text { EF* }^{*} \\
(g h a)\end{array}$ & $\begin{array}{c}\mathbf{B C}^{*} \\
(g h a)\end{array}$ & $\begin{array}{c}\mathbf{E D}^{*} \\
(g h a)\end{array}$ & $\begin{array}{c}\mathbf{E F}_{\text {size }} \\
(\text { gha })\end{array}$ & $\mathbf{E F}_{\text {depth }}$ \\
\hline ITA & 4.0 & 1.1 & 2.9 & 1.5 & 2.8 \\
USA & 9.7 & 4.7 & 5.0 & 4.2 & 2.5 \\
\hline
\end{tabular}

*source: Global Footprint Network, 2005.

Even if this is an opening study to test the 3D-EF-model for national accounts, some consideration can be preliminarily tracked in order to define the guideline for a sustainability rank among nations.

A country can be considered virtuous and closer to sustainability if:

i) the total footprint i.e. the total stress annually exerted on both, local and global, ecosystems should be as low as possible and anyway lower than local biocapacity $\left(\mathrm{EF} \leq \mathrm{BC}_{\mathrm{loc}}\right)$;

ii) the use of flow instead of stock should be always advantaged when possible. In this sense, the depth component should be as low as possible. In ideal condition this component is equal to one i.e. the natural depth $\left(\mathrm{EF}_{\text {depth }}=1\right)$;

iii) finally the consumption of resources from local ecosystems should be privileged to avoid possible future problems. Once the point of this list is respected and the total footprint is as small as possible, no particular indication can be defined for $\mathrm{EF}_{\text {size }}$ except that it should be closer to $\mathrm{EF}_{\text {tot }}$.

Even if, the model offers interesting and informative responses, several questions remain also unanswered to date. This regards above all the stock depletion and its consequences on the ecosystem productivity and well being perceived by the population. 


\section{Conclusion}

In this paper a possible way to apply the 3D-EF model to national level was offered. Two countries were also analyzed to support the hypothesis and to show the potentials of the methods.

One of the main results was to give insights on the (un)sustainability of the lifestyle of the countries investigated with especially respect to the depletion of the stocks.

This new model also opens the possibility of comparing the behavior of different populations not only with respect to $\mathrm{EF}$ and $\mathrm{BC}$ (both at local and global level): it can highlight (in)equity of appropriation of resources and ecological services between current generations of different countries (analyzing the values of $\mathrm{EF}_{\text {size }}$ ) and between current and future generations (examining the values of $\mathrm{EF}_{\text {depth }}$ ). In this sense a new Footprint geography can be drawn.

\section{References}

[1] Niccolucci V., Bastianoni S., Tiezzi E.B.P., Wackernagel M., Marchettini N, How deep is the footprint? A 3D representation. Ecological Modelling 220, 2819-2823, 2009.

[2] Wackernagel, M. \& Rees, W.E., Our Ecological Footprint: Reducing Human Impact on the Earth. New Society Publishers, Gabriola Island, BC, 1996.

[3] Rees, W.E., Ecological Footprint and appropriated carrying capacity: what economics leaves out. Environment and Urbanization 4, 121-130, 1992.

[4] Monfreda, C., Wackernagel, M. \& Deumling, D., Establishing national natural capital accounts based on detailed ecological footprint and biological capacity assessments. Land Use Policy, 21, 231-246, 2004.

[5] Galli, A., Kitzes, J., Wermer, P., Wackernagel, M., Niccolucci, V. \& Tiezzi, E., An exploration of the mathematics behind the ecological footprint. International Journal of Ecodynamics, 2(4), pp. 250-257, 2007.

[6] WWF International, Global Footprint Network, ZSL, Living Planet Report 2006. WWF, Gland Switzerland, 2006. Available at: www.panda.org/livingplanet.

[7] GFN (Global Footprint Network). Available at http://www.footprint network. org /.

[8] Kitzes, J., Wackernagel, M., Loh, J., Peller, A., Goldfinger, S., Cheng, D. \& Tea, K., Shrink and Share: Humanity's Present and Future Ecological Footprint. Philosophical Transactions of the Royal Society B, 363, 467-475, 2008.

[9] Pearce D.W., Turner, R.K. Economics of natural resources and the environment. The Johns Hopkins University Press, Baltimore, MD, 1990. 